hurst and R. M. Jarrett have investigated the effect of cover crops on fruit-tree nutrition, finding they had little effect on yield and girth increase, but lowered the nitrogen content of foliage, as compared with clean cultivation. C. Bould and J. Tolhurst bring further evidence that magnesium deficiency of fruit trees can be cured effectively by three or four foliage sprays of 2 per cent magnesium sulphate.

Prof. T. Wallace, director of Long Ashton Research Station, leads a group of workers on problems of plant nutrition, the present papers dealing mainly with the effects of farmyard manure on potatoes (with E. Catlow). E. J. Hewitt has an interesting paper on the resolution of factors in soil acidity, discussing the relative effects of aluminium and manganese toxicities. The same worker reports on iron deficiency and (with E. W. Jones) on molybdenum deficiency.

Dithiocarbamates, organic mercurials, substituted quinols and glyoxalidine derivatives have been suggested as alternatives to lime sulphur spray for the control of plant diseases. These are described in a short paper by R. W. Marsh; glyoxalidine seemed to give the most promising results. The proper healing of wounds is an important factor in plant pathology. S. H. Crowdy has studied the effect of organic chemicals on the process, and makes the suggestion that the inclusion of plant growth substance in wound dressings may have advantages. Some promising results on the control of brown rot of fruits by spraying with phenyl mercury chloride are reported by R. J. W. Byrde. The insecticide DDT has attained such popularity that it is natural to investigate the toxic properties of its analogues. This is being done by S. H. Bennett, H. Martin, A. Stringer and D. Woodcock, who issue a progress report.

A former director of the Station, Prof. B. T. P. Barker, contributes a paper on 'cider sickness', finding at least three different bacteria which can cause it. S. W. Challinor and L. F. Burroughs contribute two papers dealing with the role of nitrogen in fermentation, as part of a fundamental study of the chemistry of cider. As another part of the inquiry into cider-making processes, Margaret E. Kieser, A. Pollard and Audrey M. Stone report on the pectose activity of some apple varieties. The browning of processed pears can be avoided by quick processing, to attain temperatures which inactivate the enzymes (Dilys James and Alice Crang).

The research at Long Ashton is thus a welcome blend of fundamental and applied studies, and the report itself is informative. It is now edited by G. T. Spinks, who is to be congratulated on the maintenance of its high standard of production.

\section{HIGH-TEMPERATURE ADIABATIC CALORIMETRIC MEASUREMENTS OF THE TRANSITION METALS}

$\mathrm{T}$

HE advantage of adiabatic calorimetry is that it allows specific heats to be measured directly over small temperature intervals and thus to obtain details of the variation of specific heat with temperature. Until recently, however, because of the difficulties of adequate thermal insulation at high temperatures, accurate work with adiabatic calorimeters was not possible at temperatures above $500^{\circ} \mathrm{C}$. Further, the atomic heats of metals in the transition group, chromium to nickel, are of considerable theoretical interest; but reliable data at high temperatures exist for iron and njckel only. Two papers which appeared in the January issue of the Canadian Journal of Research ${ }^{1}$ are therefore of considerable interest. In the first, a description is given by L. D. Armstrong of the construction of a new high-temperature adiabatic calorimeter which, by making use of special techniques developed previously for the measurement of thermal conductivities at high temperatures ${ }^{2}$, can be used for making reliable determinations of specific heats up to $800^{\circ} \mathrm{C}$.

The specimen, either a machined cone of solid metal or in the form of a powder or loose pieces packed firmly together, fits into a copper container, and the specimen and container are electrically heated. The surrounding copper radiation jacket, which is maintained at a temperature as close as possible to that of the container, is supported inside an electrical furnace which can be evacuated or filled with an inert gas. Temperatures are measured by thermocouples. The heat capacity of the empty calorimeter is determined by two series of measure. ments : one with the calorimeter empty; and the other with the calorimeter filled with the standard material, aluminium oxide in the form of synthetic sapphire, the specific heat of which is known accur. ately from the work of D. C. Ginnings and R. J. Corruccini $^{3}$. It is claimed that specific heat values derived from a smoothed specific heat/temperature curve obtained from measurements made with the adiabatic calorimeter are correct to within I per cent.

In the second paper, measurements of the specific heats of chromium, manganese and cobalt made with the adiabatic calorimeter are described by $L$. $D$. Armstrong and H. Grayson-Smith. The chromium used was in the form of electrolytic flakes and was 99.9 per cent pure. The atomic heat of chromium is regular from 0 to $800^{\circ} \mathrm{C}$., increasing steadily above $100^{\circ} \mathrm{C}$. to values considerably in excess of the classical value $3 R$. For manganese, in the form of electrolytic nodules and of 99.99 per cent purity but slightly discoloured by surface oxidation, the measurements show that the atomic heat is quite regular from 0 to $700^{\circ} \mathrm{C}$. with values considerably greater than $3 R$. At $717^{\circ} \mathrm{C}$. the transition from the $\alpha$ - to the $\beta$-phase takes place sharply with a latent heat of $450 \mathrm{cal} . / \mathrm{mol}$. Supercooling occurs on cooling from the $\beta$ - to the $\alpha$-phase. Except for the interval 447$478^{\circ} \mathrm{C}$., where cobalt changes its structure on heating from hexagonal close-packed to face-centred cubic, the atomic heat increases regularly. The heat of transition was estimated to be $60 \mathrm{cal} . / \mathrm{mol}$. approximately.

The experimental values are used for a theoretical discussion of the atomic heats of the transition metals, all of which are considerably greater than $3 R$ at high temperatures. The excess specific heats of the ferromagnetic substances cobalt and nickel can be accounted for by the ferromagnetism and the conduction electrons. For chromium and manganese, after allowance is made for the conduction electrons, there is still a large residual excess specific heat indicating some unknown source of internal energy, attributed tentatively to antiferromagnetism. It is suggested that the two metals may have antiferromagnetic Curie points at temperatures above $800^{\circ} \mathrm{C}$., but there is little evidence at present to support such a proposal.

${ }^{1}$ Canadian J. Res., 28A, 44 and 51 (1950).

'Canadian J. Res., $25 \mathrm{~A}, 357$ (1947).

J J. Reg. Nat. Bur. Standards, 38, 583 (1947). 